\title{
Derivation of Global Parametric Performance of Mixed Flow Hydraulic Turbine Using CFD
}

Ruchi Khare, Vishnu Prasad and Sushil Kumar

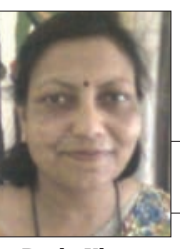

Ruchi Khare

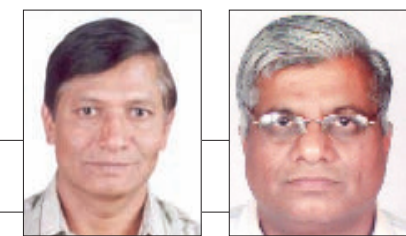

Vishnu Prasad

Sushil Kumar

Abstract: The testing of physical turbine models is costly, time consuming and subject to limitations of laboratory setup to meet International Electrotechnical Commission (IEC) standards. Computational fluid dynamics (CFD) has emerged as a powerful tool for finding numerical solutions of wide range of flow equations whose analytical solutions are not feasible. CFD also minimizes the requirement of model testing. The present work deals with simulation of 3D flow in mixed flow (Francis) turbine passage; i.e., stay vane, guide vane, runner and draft tube using ANSYS CFX 10 software for study of flow pattern within turbine space and computation of various losses and efficiency at different operating regimes. The computed values and variation of performance parameters are found to bear close comparison with experimental results.

Key words: Hydraulic turbine, performance, computational fluid dynamics, efficiency, losses

Nomenclature:

$\begin{array}{lll}\mathrm{D} & : & \text { Diameter of runner }(\mathrm{m}) \\ \mathrm{g} & : & \text { Acceleration due to gravity }(\mathrm{m} / \mathrm{sec} 2) \\ \mathrm{H} & : & \text { Net head }(\mathrm{m}) \\ \mathrm{Hl} & : & \text { Total head loss }(\mathrm{m}) \\ \mathrm{n} & : & \text { Rotational speed of runner }(\mathrm{rpm}) \\ \mathrm{Q} & : & \text { Discharge }(\mathrm{m} 3 / \mathrm{sec}) \\ \mathrm{TPi} & : & \text { Total Pressure at stay vane inlet }(\mathrm{Pa}) \\ \mathrm{TPo} & : & \text { Total Pressure at draft tube outlet }(\mathrm{Pa}) \\ \mathrm{\gamma} & : & \text { Specific weight }(\mathrm{N} / \mathrm{m} 3)\end{array}$

\section{Introduction}

The hydraulic turbine utilizes the energy of flowing water. Hydraulic machines are characterized by the nature of transference of energy between rotor and water stream. The well-designed water path from inlet to outlet of a turbine will give the best efficiency or performance. The runner is the most important component of turbine because the energy transfer takes place in the runner. The performance of a turbine depends mainly on the guiding of water to the runner, runner blade design and outlet energy from runner. The spiral casing, stay ring and guide vanes impress circulation on the flow and in the process, create non-uniform flow at runner inlet. It is customary, therefore, to understand the effect of the guide vane opening on the flow reaching the runner to improve its performance. As the energy transfer takes place in the runner, it is important to design the runner as efficient as possible. The water flow from the guide vanes on to the runner blades, which are curved in opposite direction to that of guide vanes, causes pressure difference on the blade surfaces and the resulting reaction rotates the runner.

The flow inside the turbine space is very complex, unsteady and three dimensional, and difficult to predict exact flow behavior (Rajoo and Martinez-Botas 2008). The numerical simulation of $3 \mathrm{D}$ flow in turbo machinery is extensive and requires substantial effort in preparing geometric inputs for analysis. It is validated (Rao and Tripathi 2007:196-201, Oh and Yoon 2007:587-590) and can be used to verify suitability of an existing or new design and also to optimize it [Wu et al 2007: 159-168).

A CFD package (ANSYS CFX 10) has been used for flow analysis in the turbine space for performance evaluation of Francis turbine in terms of global parameters in the present work. The RANS equations are solved using finite volume method in this software (ANSYS 2005). The CFD results have been compared for efficiency with experimental results (Shukla 2007) and bear close comparison. The variation of losses in different turbine components and efficiency at different operating regime are studied.

\section{Geometry and mesh generation}

The 3D geometry of turbine space and components is created on ANSYS Workbench 10. The modeling of a complete turbine as a single component is a difficult task as casing, stay vane, guide vane, draft tube are stationary while the runner is rotating. Thus, it is required to model the turbine by parts, namely: stay vane, guide vane, runner and draft tube as separate domains; then, assembly is done through the interfaces for simulation. The modeled Francis turbine consists of 18 stay vanes, 18 guide vanes, 13 runner blades and a draft tube. The casing is not considered for modeling due to limitation of computational facility. The diameter of runner is 1010 $\mathrm{mm}$. The specific speed of turbine is 266.19 (m-kW-rpm units) and the rated speed factor and discharge factor of turbine are 27.92 and 0.3275 , respectively. The profile of the blades is aerofoil and to model this, it is required to generate 3D sectional co-ordinates along its length based on the theoretical design of blade in a data file. These points are taken on ANSYS Workbench and joined to develop 3D blade geometry. The same approach is adopted for other curves like shroud, hub and casing. 
To analyze turbine at different guide vane opening, it is required to change the geometry of guide vane domain for each guide vane opening (GVO). The geometry of all other parts such as stay vanes, runner and draft tube remains same but assembled with changed guide vanes to analyze at different guide vane openings. The 3D runner geometry and complete assembled geometry of turbine are shown in Figures 1 and 2.

The mesh generation is a technique to discretize the whole domain into small elements of required shape

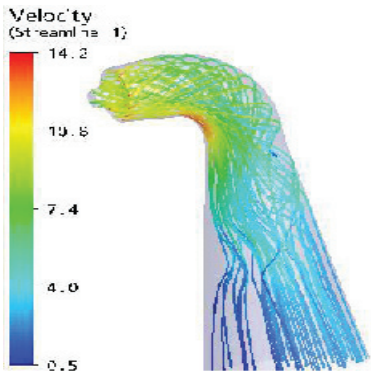

Figure 1. Runner

Domain Geometry

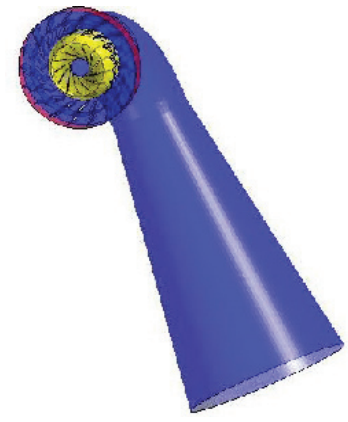

Figure 2. Assembled Turbine Geometry and size. The vertices of these elements form nodes at which all the unknown variables are calculated. The quality of mesh affects the accuracy of solution to a large extent and hence mesh quality checks are done. The unstructured mesh of tetrahedral elements in all components has been used and generated in

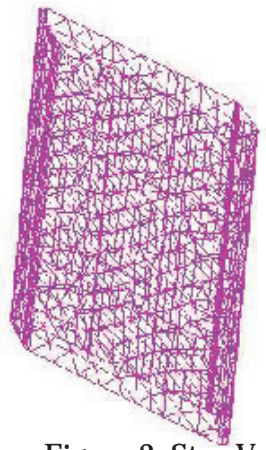

Figure 3. Stay Vane Mesh

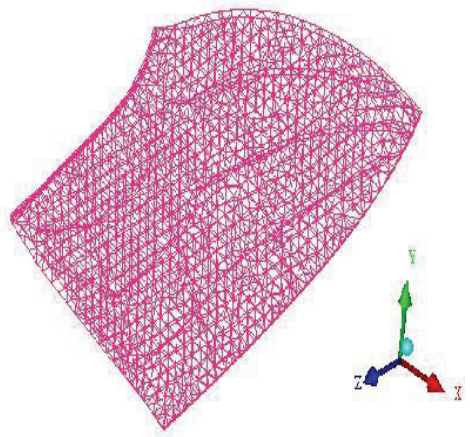

Figure 5. Runner Blade Mesh

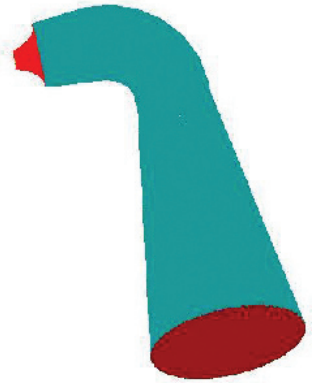

Figure 6. Draft Tube Mesh

\begin{tabular}{|c|c|c|}
\hline Domain & No. of Nodes & $\begin{array}{c}\text { No. of } \\
\text { Elements }\end{array}$ \\
\hline Stay vane & 72349 & 351778 \\
\hline Guide vane & 71271 & 353139 \\
\hline Runner & 223375 & 1065576 \\
\hline Draft tube & 98472 & 536252 \\
\hline
\end{tabular}

Table 1. Mesh Statistics in Present Study

\section{Boundary conditions}

The boundary conditions are to be specified for each run and the nature of solution and accuracy depend on the way in which these conditions are specified.

The boundary conditions used in present analysis are given as mass flow rate at stay vane inlet and static pressure at the draft tube outlet as mentioned in Table 2. The rotational speed of runner is specified as per the regime of operation varying from $400 \mathrm{rpm}$ to $900 \mathrm{rpm}$ for each guide vane opening. The stay vane, guide vane and draft tube domain are taken as stationary. The SST $\kappa-\omega$ turbulence model has been used for analysis because of high curvatures in flow passage. The walls of all domains are assumed to be smooth with no slip condition.

\section{Equations used}

The following formulae are used for computation of global parameters in non-dimensional form for performance assessment of turbine.

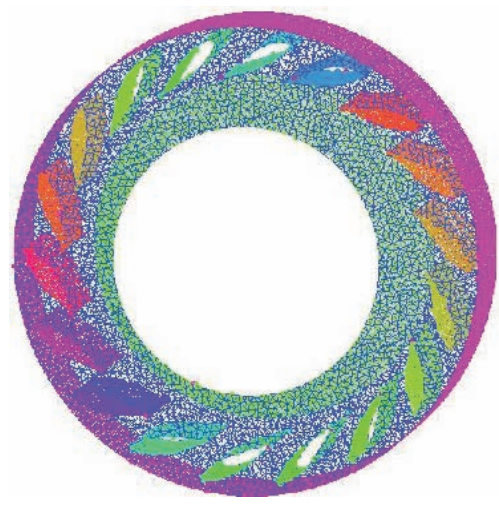

Head

Hydraulic efficiency $\quad \mathrm{H}=\frac{\mathrm{TP}_{\mathrm{i}}-\mathrm{TP}_{\mathrm{o}}}{\gamma}$

Speed factor $\quad \eta_{\mathrm{h}}=\frac{\mathrm{H}-\mathrm{H}_{\mathrm{t}}}{\mathrm{H}} \times 100$

Discharge factor

Specific energy coefficient

$$
\psi=\frac{\mathrm{gHD}^{4}}{\mathrm{Q}^{2}}
$$

The losses in individual components are computed Figure 4. Guide Vane Mesh using total pressure difference between the inlet and outlet of respective components. 


\section{Results and discussions}

The CFD analysis is carried at optimum as well as at off design regimes. The tested optimum efficiency regimes of turbine is at $80.93 \mathrm{~mm}$ GVO and speed factor

\begin{tabular}{|l|l|l|}
\hline Boundary name & Inlet & Outlet \\
\hline Location & Stay vane inlet & Draft tube outlet \\
\hline & Mass flow rate & \\
Parameter & $5930 \mathrm{Kg} / \mathrm{s}$ at $66.73 \mathrm{~mm}$ GVO & Static pressure as $10^{5} \mathrm{~Pa}$ \\
specified & $7200 \mathrm{Kg} / \mathrm{s}$ at $80.93 \mathrm{~mm}$ GVO & \\
& $8000 \mathrm{Kg} / \mathrm{s}$ at $91.57 \mathrm{~mm} \mathrm{GVO}$ & \\
\hline
\end{tabular}

Table 2. Boundary Conditions

value of 27.92. The numerical flow analysis is carried out for three guide vane openings; i.e., $66.73 \mathrm{~mm}, 80.93 \mathrm{~mm}$ and $90.47 \mathrm{~mm}$ GVO and six speeds varying from $400 \mathrm{rpm}$ to $900 \mathrm{rpm}$. The computed efficiency from CFD results at maximum efficiency regime without casing for three guide vane openings are compared with experimental values obtained with casing. The optimum operating regime obtained from $\mathrm{CFD}$ and experimental results is the same. The pressure variations along flow direction; i.e., in meridional space and mid section of runner blade for maximum efficiency regime of operation are shown

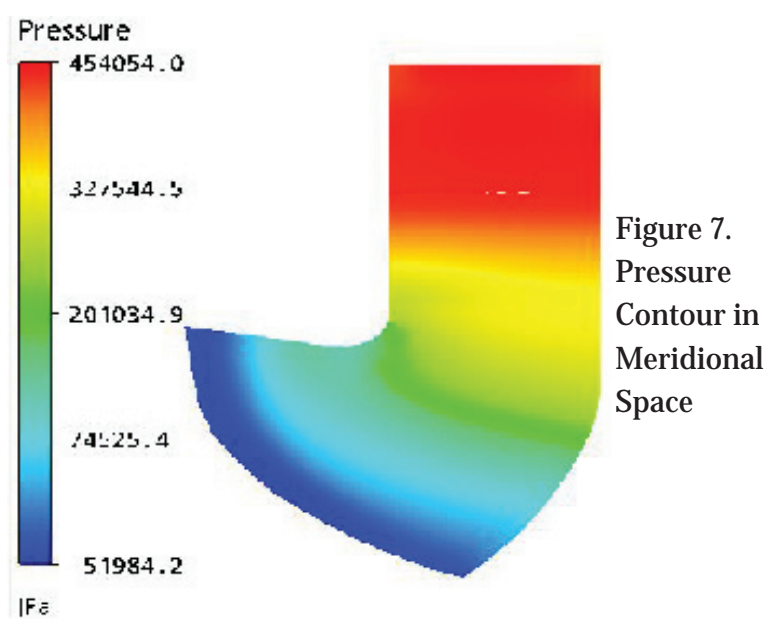

$\mid F \bar{z}$

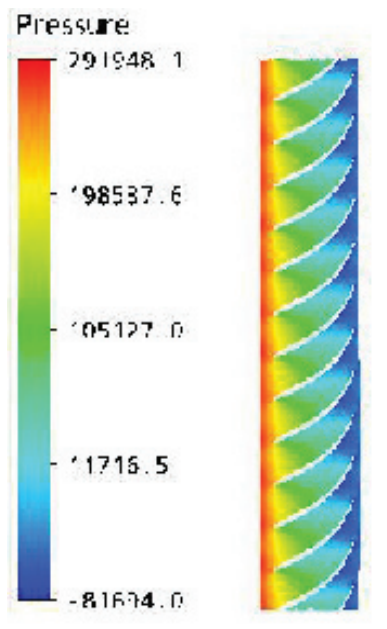

Figure 8. Pressure Contour Over Runner. in Figures 7 and 8. These figures show that pressure is in decreasing order from inlet to outlet of turbine and runner as well. The pressure drop in runner domain is more because of energy extraction from flowing water.

The tabulated data (Table 3) show very close comparison between the computed and experimental efficiency at all guide vane openings.

Thelossesinstayvanedecreasewithdecrease of guide vane opening and slightly increase with speed factor. This is due to increase in discharge with guide vane opening and, hence, increase the velocity due to constant stay vane opening causing more friction losses, as shown in Figure 11. In case of guide vanes, the losses shown in Figure 12 are decreasing with increase of guide vane opening, and are again due to high velocity at low guide vane opening as discharge is specified at inlet. This means that losses in stay vane and guide vane are mainly due to friction and are proportional to kinetic head. The losses in runner

\section{Veloc'ty}

(st -eaml 7 1)
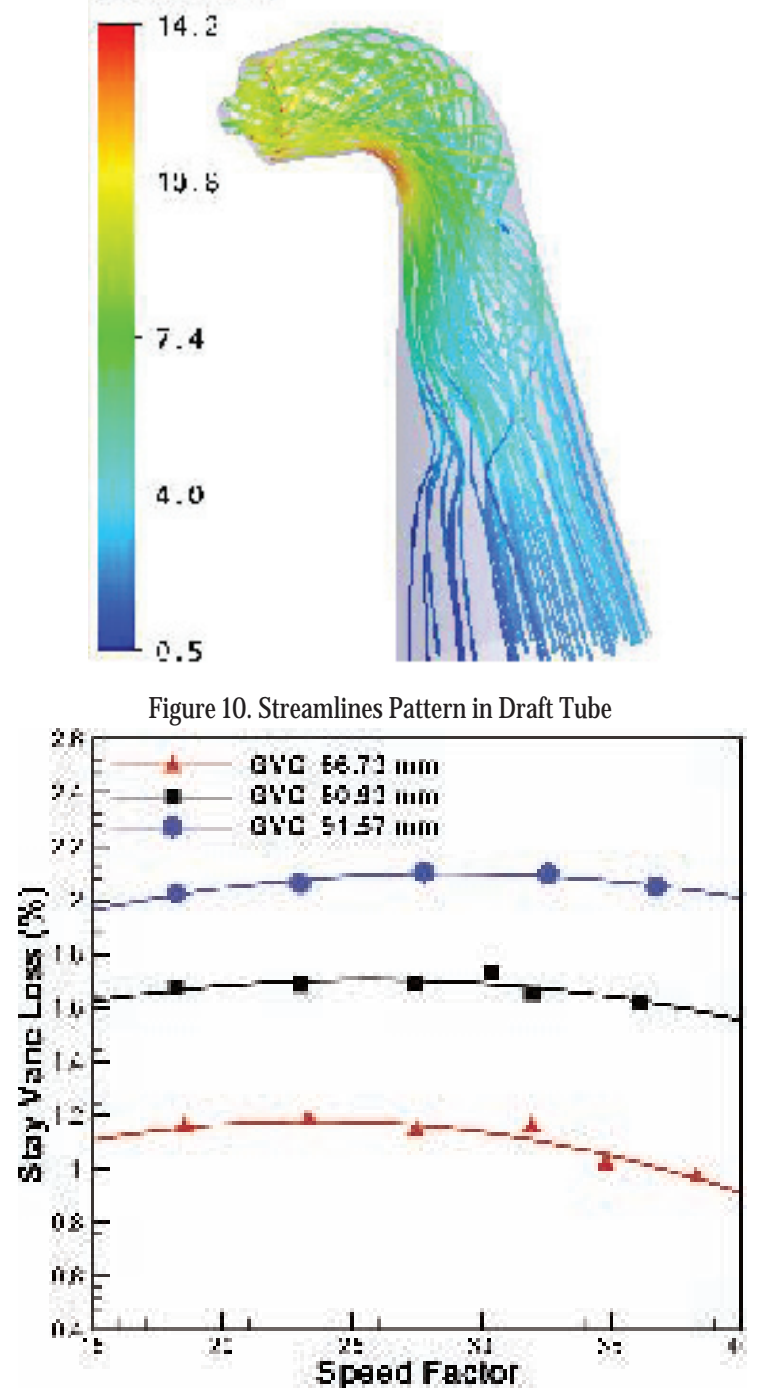

Figure 11. Variation of Stay Vane Losses 


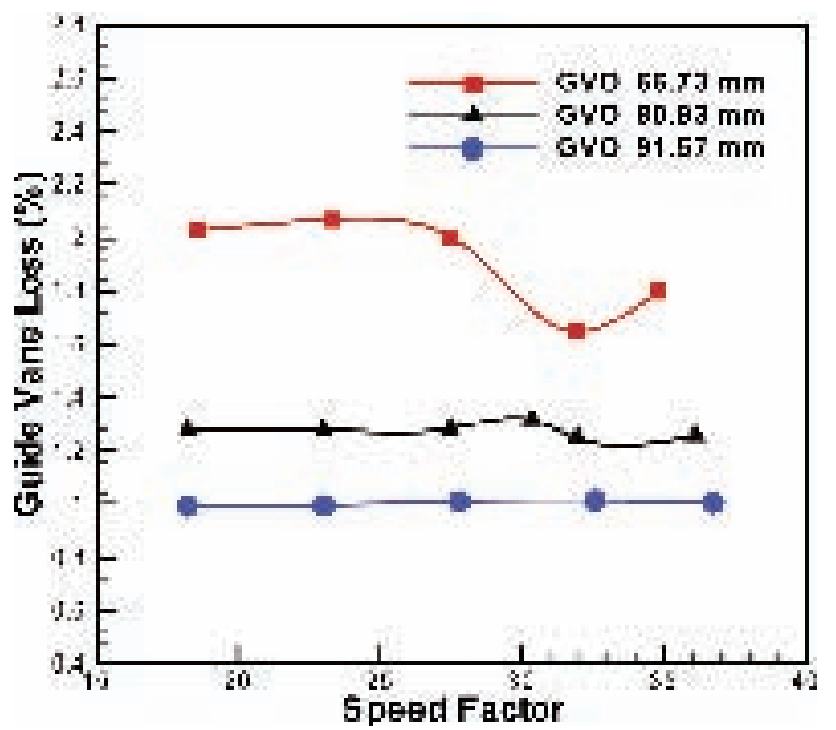

Figure 12. Variation of Guide Vane Losses

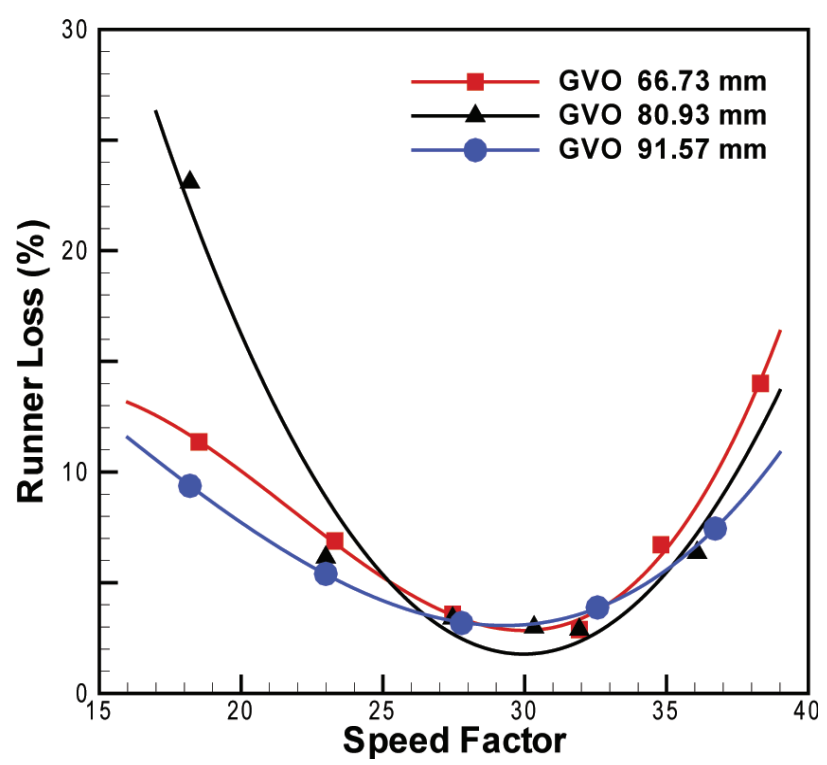

Figure 13. Variation of Runner Losses

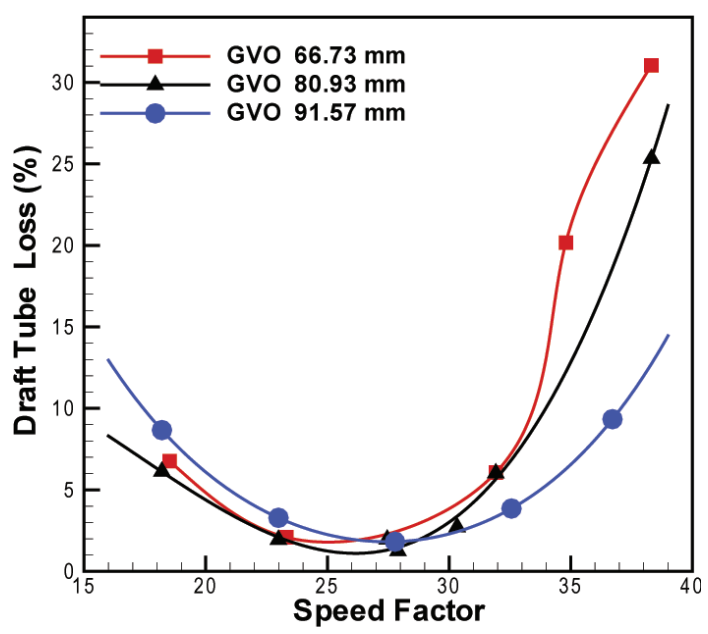

Figure 14. Variation of Draft Tube Losses

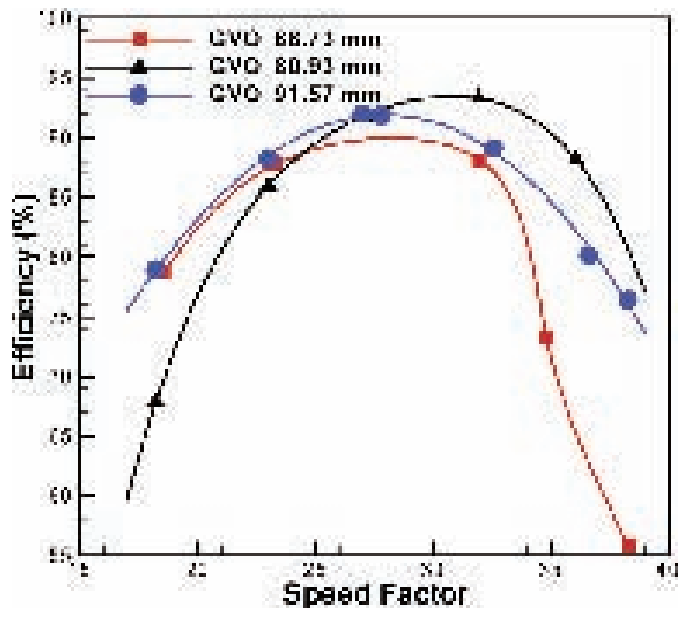

Figure 15. Variation of Efficiency

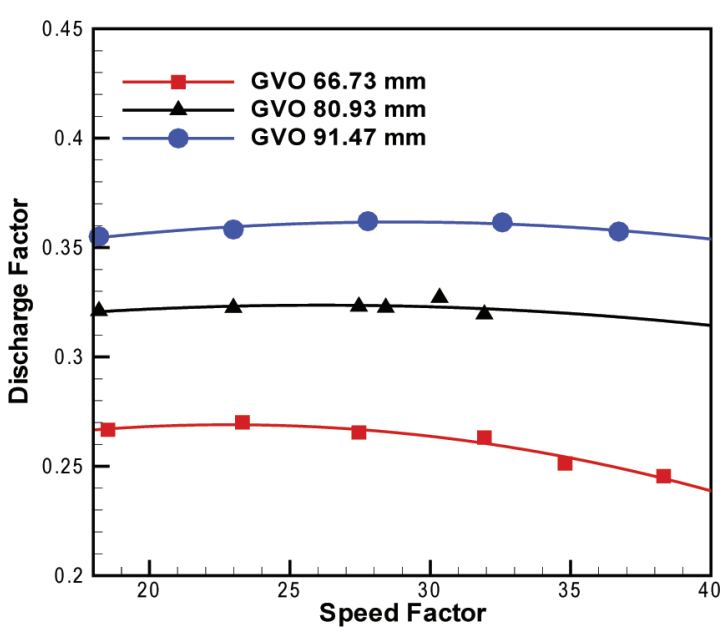

Figure 16. Variation of Discharge Factor

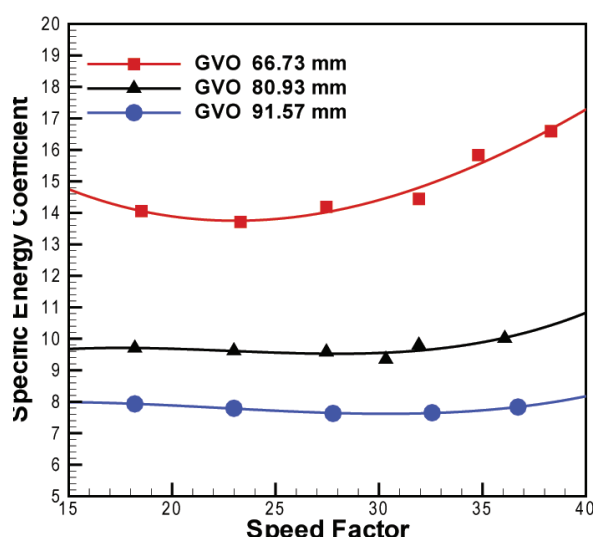

Figure 17. Variation of Specific Energy

\begin{tabular}{|l|c|c|c|}
\hline Guide vane opening $(\mathrm{mm})$ & 66.73 & 80.93 & 91.57 \\
\hline Speed factor $\left(\mathrm{n}_{\mathrm{ED}}\right)$ & 27.92 & 27.92 & 27.92 \\
\hline Discharge $(\mathrm{m} 3 / \mathrm{sec})$ & 5.930 & 7.200 & 8.000 \\
\hline Computed Efficiency $(\%)$ & 88.06 & 92.00 & 91.80 \\
\hline Experimental efficiency $(\%)$ & 90 & 92.60 & 91.70 \\
\hline
\end{tabular}

Table 3. Comparison of Results 
and draft tube, as shown in Figures 13-14, are having parabolic pattern for all guide vane openings and have minimum values near the speed factor corresponding to maximum efficiency. This pattern of losses in runner is due to increase in shock loss at speeds, other than rated speed of turbine. The parabolic loss variation in draft tube is due to high whirl velocity from runner outlet at off-design regimes.

The efficiency variation in Figure 15 indicates that maximum efficiency occurs at the speed factor where losses in runner and draft tube are minimal. It means that losses in runner and draft tube plays important role on the performance of turbine.

The discharge factor as shown in Figure 16 is slightly increasing with increase in speed. Its value is increasing with increase in guide vane opening.

The specific energy coefficient in Figure 17 decreases with increase in guide vane opening because of increased flow area and decrease in frictional losses. It is nearly independent of rotational speed at more guide vane opening but varies gradually with increase in rotational speed of runner due to increase in frictional and shock losses at less guide vane openings.

\section{Conclusions}

The computed efficiency values at maximum efficiency regimes for three guide vane openings are close to that of experimental values and hence validate CFD analysis in turbine flow passage. The efficiency characteristics from CFD simulations are very similar to that obtained in experimental testing of Francis turbine models.

The losses in stay vane and guide vane are mainly due to friction while thelosses in runner and draft tube depend on shock at runner inlet and whirl velocity at runner exit respectively. It is also seen that losses in runner and draft tube are more influential for performance as compared to the losses in other parts of the turbine.

Mrs Ruchi Khare, M..Tech., Asst. Professor in Maulana Azad National Institute of Technology,Bhopal , India (MANIT) is presently pursuing research in hydraulic turbines. She has 12 years of experience in teaching, consultancy and research at MANIT, Bhopal. She has published 20 papers in International/ National journals/ conferences.

Corresponding address: ruchif4@rediffmail.com

Vishnu Prasad, Ph. D., AssociateProfessor in MANIT, Bhopal. Presently, pursuing research in hydraulic turbines and water resources. He has 20 years of experience in teaching, consultancy and research at S.V. National Institute of Technology, Surat and MANIT, Bhopal. He had been to UK for training on model testing and CFD for six months. He has published 41 papers in International/National journals/conferences and guided $43 \mathrm{M}$. Tech dissertations.

Corresponding address: vpp7@yahoo.com

Sushil Kumar, Ph.D., Professor in MANIT, Bhopal. He has 35 years of experience in teaching, consultancy and research at MANIT, Bhopal. He has published 63 papers in International/ National journals/ conferences and guided $30 \mathrm{M}$. Tech dissertations and $3 \mathrm{PhDs}$. He is co-coordinator at MANIT, Bhopal for State Technical Agency to Prime Minister's Village Road Project. Corresponding address: vpp7@yahoo.com

\section{References}

ANSYS, 2005, ANSYS CFX 10 Software Manual, Canonsburg, PA (USA): ANSYS, Inc., and New Delhi, India: ANSYS Software Pvt. Ltd.; URL: www.ansys.com.

Guoyi Peng, 2005, A Practical Combined Computation Method of Mean Through- Flow for 3D Inverse Design of Hydraulic Turbo machinery Blades, J ournal of Fluids Engineering 127:1183-1190.

Horlock, J.H. and J.D. Dento, 2005, A review of some early practices in computational fluid dynamics, Journal of Turbo Machinery 127(1):5-12.

Lewis, R.I., 1991, Vortex Element Methods for Fluid Dynamic Analysis of Engineering Systems, Cambridge, UK: Cambridge University Press.

Lewis, R.I., 1995, Developments of actuator disc theory forcompressibleflowthroughturbo-machines, International J ournal of Mechanical Science, 37(10):1051-1066.

Oh,H.W.andE.S.Yoon,2007,Application ofcomputational fluid dynamics to performance analysis of a Francis turbine, J ournal of Power and Energy 399:587-590.

Rajoo, S. and R. Martinez-Botas, 2008, Mixed flow turbine research: A Review, J ournal of Turbo Machinery 130(10):44001-440012.

Rao V.S. and S.K. Tripathi, 2007, Role of CFD analysis in hydraulic design optimization of hydro turbines, Proceeding of National Seminar on CFD-The 3rd Dimension in Flow Analysis \& Thermal Design, RGPV, Bhopal (India), pp.196-201.

Shukla, M., 2007, CFD Analysis of 3D flow and its validation for Francis turbine, M. Tech. Thesis, Department of Civil Engineering, Maulana Azad National Institute of Technology, Bhopal (India).

Wissing, J.G. and W. Rodi, 2006, Direct numerical simulation of transitional flow in turbo machinery, Journal of American Society of Mechanical Engineers 128(10):668-678.

Wu, J ., K. Shimmei, K. Tani and K. Niikura, 2007, CFD based design optimization of hydro turbines, J ournal of Fluids Engineering 129(2):159-168 